\title{
Nietzsche y el automatismo instintivo
}

\author{
PABLO MARTÍNEZ BECERRA \\ Universidad de Playa Ancha (Chile) \\ pablo.martinez@uai.cl
}

\begin{abstract}
Resumen
En este artículo se expone la valoración nietzscheana del «automatismo instintivo» y la «conciencia». Se pone de manifiesto la positiva valoración que Nietzsche hace de la actividad corporal, expresada en los instintos, frente a la «racionalidad-consciente».
\end{abstract}

Palabras claves: Nietzsche, automatismo, instinto, conciencia, razón.

\section{Nietssche and the instinctive automatism}

\begin{abstract}
This paper is about Nietzsche's evaluation of the «instinctive automatism» and «conscience». It highlights Nietzsche's positive evaluation of corporal activity, which is revealed by the instincts, as opposed to «rationality-conscious».
\end{abstract}

Key words: Nietzsche, automatism, instinct, conscience, reason.

Doctor en Filosofía por la Universidad de Valencia (España). Actualmente se desempeña como profesor de la Facultad de Humanidades de la Universidad de Playa Ancha. Entre sus publicaciones cabe mencionar los libros Nietzsche y el despliegue de la libertad (2007) y Nietzsche, descenso a Dioniso y ascenso trágico (2008). 
Es ya consabida la prioridad que tiene el cuerpo en el pensamiento de Nietzsche, sobre todo desde el momento en que ha considerado ilusorias las llamadas «facultades espirituales». Para él, el cuerpo es el centro de la actividad vital. Precisamente, en estas líneas queremos ahondar en la concepción nietzscheana del cuerpo y, para ello, prestaremos atención a su modo de operar.

Nuestro punto de arranque será, en primer lugar, mostrar el modo en que algunos filósofos han explicado el movimiento animal en términos puramente mecánicos. Creemos que esto es conveniente, si, efectivamente, le damos crédito a Nietzsche cuando afirma que ese es el único modo de asegurar la probidad investigativa desde el inicio. Es decir, le concedemos que si no somos mecanicistas en un comienzo, partimos de una posición deshonesta que dificulta que entendamos el fenómeno animal y humano. Recordemos que Nietzsche analizando a Descartes, sostiene que «lo que hoy se ha llegado a entender del hombre llega exactamente hasta donde se lo ha entendido como máquina» ${ }^{1}$.

Lo dicho anteriormente significa que Nietzsche defiende, en coincidencia con Lange, que «materialismo», «sensualismo» y «mecanicismo» sirven de principios heurísticos de indagación en ciencias naturales y, a la par, en filosofía. Sin duda, ninguna de estas posiciones son asumidas por Nietzsche, es más son atacadas, pero, el filosofo alemán, considera que todas ellas dan la posibilidad de elevarse a una posición antidualista que asegure su lugar al cuerpo.

A nuestro entender, el debate renacentista, iniciado, como veremos, por Gómez Pereyra, en torno al «automatismo mecánico del animal» que es opuesto a la vida "psíquica racional humana», posibilita plantear la discusión. Preguntarse cómo puede desenvolverse un ser «desalmado» de un modo tan perfecto o cómo se puede explicar el despliegue animal sin sensibilidad y desarrollando su vida nada más que al modo de una máquina, son cuestiones que se intentan responder.

Sin embargo, esta discusión inicial, nos ha de llevar al problema insistentemente planteado por Nietzsche, como es el del lugar que ocupa la conciencia en la vida humana. Al llegar aquí, la discusión ya no se plantea en los términos de una oposición entre, por una parte, la actividad mecánica y automática del cuerpo y, por otra, la vida racional (Descartes), sino oponiendo una suerte de «automatismo instintivo» a la vida consciente. Lo que nos ocupa acá es responder si acaso la vida consciente es un añadido, si la vida es más perfecta en ausencia de ella, debido a que son cuestiones centrales en la revalorización del cuerpo hecha por Nietzsche.

1 F. NiETZSCHE: El anticristo. Alianza, Madrid 1978, \ 14, 38. (En adelante A). 
Para Nietzsche, el cuerpo tiene una actividad mucho más sutil, perfecta y «automática» que el operar que se ejerce de ese centro que llamamos «conciencia». Pero, como veremos, ese despliegue corporal automático lejos está de ser esa reacción mecánica y reactiva que el pensamiento cartesiano le atribuye. En definitiva, cómo se desenvuelve esa sutil trama vital a los ojos de Nietzsche es lo que aquí pretendemos describir.

\section{Automatismo mecánico y movimiento animal}

Huxley, en pleno siglo XIX, daba cuenta de las grandes posibilidades que tienen los organismos para desenvolverse sin necesidad del razonamiento y la sensibilidad ${ }^{2}$. Se apoyaba en un experimento bastante sencillo, tanto así que para muchas generaciones de escolares fue un experimento biológico recurrente, aunque no por ello poco intrigante, a saber: «mostraba a sus auditores una rana privada de sus hemisferios cerebrales la que, sin embargo, realizaba prodigiosos movimientos para mantener el equilibrio apoyándose en las manos, sin caer, a pesar de los giros que la mano realizaba en diversos sentidos» ${ }^{3}$.

Como destacaba Fouillée, la posibilidad de mostrar el carácter accesorio del placer, del dolor, de la sensibilidad y que el animal podría funcionar igual sin la presencia de ellos, significaba para el fisiólogo inglés, asegurar que lo esencial en la vida animal pertenece a la esfera puramente «natural» o mecánica. Dicho de otra manera, Huxley promovía la idea del carácter accesorio de la «vida psíquica».

Podría alguien confundirse y pensar que Huxley está defendiendo que el bruto sería un «animal-máquina» o «autómata», es decir, un ser que actúa con ausencia de sensibilidad. Por ello, hay que aclarar, siguiendo el análisis de Fouillée, que en rigor las tesis planteadas por el científico inglés son, por un lado, que el animal se movería de un modo más perfecto si efectivamente lograse comportarse como un autómata insensible y, por otro, que mientras sus funciones psicológicas son prescindibles, las fisiológicas son insustituibles. Además, sería muy difícil pensar que Huxley esté negándole sensibilidad a la rana, cuando,

2 Cfr. A. FoullléE: “L'Homme automate", Revue des Deux Mondes, no 60/16 (1886), 548. [Hay traducción castellana inédita que es justamente la que usamos aquí. Ha sido realizada por Audrey Jeannet y Carlos Medel].

3 Ibíd. 
justamente, para poder observarla insensible le quita sus hemisferios cerebrales ${ }^{4}$.

La pregunta que nos interesa abordar, primeramente, es en qué puede consistir la actividad animal si se la entiende en términos puramente fisiológicos y mecánicos. Para responder esta pregunta nos remontamos al precursor del llamado «automatismo animal» como es Gómez Pereyra que, como es bastante sabido, se anticipa a René Descartes en este asunto. En otras palabras, Pereyra es el primero en defender que la sensibilidad no es un atributo del animal.

\section{Automatismo y sensibilidad}

Ciertamente, como dijimos más arriba, Huxley no está afirmando la insensibilidad animal, pero, sí está sosteniendo que provocando el cese de dicha actividad sensitiva no sólo los movimientos son posibles, sino que devienen más seguros y perfectos. Como veremos, esto último no lo afirma Pereyra, pero advertimos en su pensamiento un esfuerzo, a ratos sin destino, de llegar a explicar cómo el animal, careciendo de verdadera vida psíquica, puede moverse sin problema alguno. Recordaremos, entonces, a grandes trazos, el pensamiento del médico español.

En el año 1554 el médico español Gómez Pereyra publica en Medina del Campo, el libro Antoniana Margarita. Escrito que, por sus diversas propuestas filosóficas, se ha prestado para altas disputas psicológicas y gnoseológicas. Pese a todo, las controversias que ha suscitado, sobre todo en el asunto del llamado «automatismo animal», si bien en su época fue discutido y difundido en toda Europa, se han desarrollado a instancias de las semejanzas que guarda con Descartes en la solución a este asunto.

Pereyra es claro: la sensibilidad tiene demasiadas implicancias como para pertenecer al animal. Como si olvidase, por un lado, los alcances y atributos que una larga tradición ha dado a los «sentidos internos» $y$, por otro, el carácter específico de las funciones de la racionalidad humana, Pereyra concibe que ciertas funciones sólo pueden ser entendidas perteneciendo a la «racionalidad».

El P. Sánchez Vega, ha sistematizado de la siguiente manera los juicios y sus consecuencias inadmisibles esgrimidos por el filósofo

4 Ahora bien, difícilmente uno podría aceptar que una rana sin cerebro continúe siendo una rana o que un animal privado de sensibilidad sea animal.

5 Usamos el extracto de la obra Antoniana Margarita, hecho en la Revista de Filosofía (CSIC), No 50, Madrid 1954, 463-508. A esta edición le antecede "Un estudio comparativo de la concepción mecánica del animal y sus fundamentos en Gómez Pereya y Renato Descartes” realizado por el R. P. Miguel Sánchez Vega, S. M., 358-461. 
español que hacen necesario que él postule su tesis del automatismo animal: «A. si el animal siente, tiene inteligencia», «1. El animal, en ese caso juzgaría como los hombres», «2. Si el bruto siente, conoce el universal», «3. Si el bruto siente, discurre» ${ }^{6}$. Dicho de otro modo, Pereyra piensa que las consecuencias son claras y concluyentes, por una parte, si los brutos sienten son semejantes a los hombres, por otra, si los brutos no son autómatas poseen racionalidad. De aquí se saca una conclusión bastante sencilla, pero grave, a saber: no hay anima sensitiva ${ }^{7}$. Es decir, todo lo que se le atribuye a la «sensibilidad interna» y a la «externa», sólo puede corresponder a funciones racionales. Por tanto, el bruto no conoce, porque, al entender del autor del Antoniana Margarita, conocer es conocer racionalmente. La actividad anímica es siempre racional y la actividad del cuerpo no puede ser anímica.

Surge la natural inquietud de cómo se ha de entender esas diversas manifestaciones aparentemente cognoscitivas del animal, desde una perspectiva puramente mecánica. A Pereyra no le queda otra salida que entender ese movimiento que se divisa de carácter anímico sensible, como una derivación de una «cualidad oculta». El animal se mueve mecánicamente, desde una fuerza que es «como la cualidad oculta que conduce al hierro al imán» ${ }^{8}$. Por tanto, el devenir animal es una simple reacción al entorno. Büchner, interpretando el Antoniana Margarita de

6 Además, el P. Sánchez Vega incorpora en su resumen la línea de argumentación de Gómez Pereyra, que, según se cree, fue recogida, en parte, con mayor atención por Descartes, a saber: «B. Si el animal siente, goza de un alma indivisible», «1. La percepción de la totalidad exige un alma indivisible», «2. La sensación táctil requiere de un alma indivisible», «3. La percepción de la cantidad arguye la indivisibilidad del alma», «4. Idéntico proceso basado en la sensación de calor y de frío» (el autor agrega luego, «c. Otros absurdos que se siguen de la sensibilidad animal» y «B. Pruebas positivas»). J. Chevalier en su Historia del pensamiento (v. III, El pensamiento Moderno de Descartes a Kant. Aguilar, Madrid 1969, 117), nos informa que Descartes en carta la Mersenne del 23 de junio de 1641, declara no haber visto el Antoniana Margarita.

7 Cfr. P. Laín Entralgo: Historia de la medicina. Salvat, Barcelona 1982, 259. Pero, extrañamente, aunque se vuelve imposible defender seriamente la existencia de la vida sensitiva, para Gómez Pereyra el animal no es un «desalmado» y, además, su «movimiento [...] obedece a cuatro causas: a las especies producidas por los objetos en los órganos sensitivos, a los fantasmas, al hábito o al amaestramiento, y, finalmente, a ciertos impulsos instintivos (efectos de la dirección de una causa extrínseca inteligente)», P. M. F. MANZANEDO O.P.: "Breve historia de la psicología en España", en R. E. Brennan O.P., Historia de la psicología. Morata, Madrid 1969, 279-280.

8 G. Pereyra: Antoniana Margarita, col. 48, 474. Cfr. M. SÁnChez VegA: "Un estudio comparativo de la concepción mecánica del animal y sus fundamentos en Gómez Pereya y Renato Descartes", 399; G. FraILE: Historia de la filosofía. Del Humanismo a la Ilustración. v. III, BAC, Madrid 1966, 359; Z. GONZÁLEZ: Historia de la filosofía. v. III, Agustín Jubera, Madrid 1886, 54. 
Pereyra y a Descartes, junto con confirmar lo anterior, sostiene que, para ambos autores, «los animales hacen muchas cosas mejor que los hombres, pero esto únicamente en virtud de un instinto ciego, de una impulsión mecánica impresa a sus órganos» ${ }^{9}$. Para Pereyra, hay un correlato entre esos movimientos animales y una suerte de anima mundi ${ }^{10}$, es decir, el devenir del animal viene a ser parte de su manifestación.

A nuestro entender, los movimientos aparentemente generados desde la sensibilidad, se dan, en la concepción de Pereyra, de modo similar a como se generan, por ejemplo, las fluctuaciones de las mareas u otros fenómenos gravitacionales. Desde aquí el animal realiza todas esas extraordinarias actividades que, para Pereyra, de ser verdaderamente cognoscitivas, tendrían que explicarse desde la razón.

Ahora bien, si Pereyra acepta la explicación del movimiento animal desde el instinto (instinctum naturalem), lo hará, sólo si se entiende éste como una tendencia que no difiere de la atracción magnética. Sólo de esta forma, por ejemplo, podremos aceptar que la cría se dirija tendencialmente a su madre y eluda lo adverso. Por tanto, Pereyra defiende que el perseguir o el rehuir propio del animal no se produce «a causa de una sensación o estimación», sino en «virtud de una propiedad física»» ${ }^{11}$.

Esta perspectiva renacentista, establece que la actividad sensible —integrada ya a la esfera racional - implica «conciencia». «Concedida la sensibilidad, hay que conceder a los brutos la conciencia. Conocerán que ven, conocerán que oyen; podrán juzgar de sus propios actos y distinguir los accidentes de la substancia» ${ }^{12}$.

\section{Automatismo y conciencia}

Este modo de «automatismo animal» que acabamos de describir, posee una índole mecánica y en ningún grado o modo puede ser calificado de psíquico. Y, podemos añadir, que supone la actividad del cuerpo separada de la vida anímica.

Las consecuencias de este modo de pensar son múltiples: la actividad corporal se circunscribe a una espontaneidad ciega, la sensibilidad no

9 L. BÜCHNER: La vida psíquica de las bestias. F. Sempere y Ca., Valencia s/d., 4.

10 G. Pereyra: Antoniana Margarita, col.138. Cfr. M. SÁnChEZ VeGA: "Un estudio comparativo de la concepción mecánica del animal y sus fundamentos en Gómez Pereya y Renato Descartes", 399.

11 Ibíd., col.16. (Aquí sigo la traducción parcial de la Antoniana Margarita aparecida en J. MARÍAS: La filosofía en sus textos. De Tales a Galileo. Labor, Barcelona 1963, 765).

12 Trozo del Antoniana Margarita citado por M. Menéndez Pelayo: La ciencia española. Polémicas, proyectos y bibliografía. v. II, Emecé, Buenos Aires 1947, 210. 
existe como tal, sólo hay vida realmente psíquica si ésta es consciente, no puede haber conocimiento sensible, la actividad judicativa y estimativa sólo pertenece a la vida consciente, etc. En otras palabras, el automatismo-maquinal supone que lo inconsciente es mecánico.

A Pávlov, el hecho de postular la idea de animales-máquinas por parte de Descartes - y Pereyra diríamos nosotros- le permite afirmar que la idea de «reflejo» procede de él ${ }^{13}$. «Hace trescientos años -expresa Pávlov-, Descartes, considerando que la actividad de los animales —en oposición a la del hombre- era automática, estableció la noción de reflejo, acto fundamental del sistema nervioso» ${ }^{14}$. Las conductas animales son, entonces, para todo aquel que postule el automatismo animal, movimientos reflejos frente a estímulos. Por ello, no es de extrañar que aquello que Pávlov atribuye a Descartes, el médico balear -nacionalizado francés- José María Guardia, se lo asigne a Pereyra. En la Revue Philosophique de 1889, nos reseña Iriarte, Guardia establecía que el autor del Antoniana Margarita ues el inventor de la insensibilidad animal, y poseía plenamente la teoría de los reflejos $[\ldots]{ }^{15}$.

Llegada la reflexión a este nivel, es oportuno volver al comienzo, a lo que Fouillée había puesto de relieve, es decir, a la amplia aceptación decimonónica de esa visión que hace del sistema nervioso lo único que vitalmente importa en el movimiento animal. Como consecuencia de esto, muchos consideran que es posible prescindir, en el despliegue de los movimientos animales y en sus diversas funciones, de la vida conciente y «mental», no sólo en el animal, sino también en el ser humano. Es decir, desde esas reflexiones de Pereyra acerca de la posibilidad de explicar el desenvolvimiento animal desde las propiedades físicas, llegamos a la pregunta de si acaso pensar, sentir, razonar es completamente accesorio. Si la rana, como sostiene Fouillée interpretando el pensar de Huxley, realiza sus diversos movimientos «de tan buena manera sin tener ni razón, ni sensación, ni pensamiento de ninguna especie», ¿no serán acaso estas funciones psíquicas un estorbo?

En resumen, tanto para Huxley como para Pereyra, la base del movimiento animal es el reflejo que, como tal, carece de elemento mental. El reflejo, para decirlo esta vez con Ribot, como «acontecimiento nervioso existe en sí mismo» ${ }^{16}$.

\footnotetext{
13 I. PÁvlov: Fisiología y psicología. Alianza, Madrid 1970, 172.

14 Ibíd., 95.

15 J. IRIARTE: Menéndez Pelayo y la filosofía española. Razón y Fe, Madrid 1947, 248.

16 Cfr. A. FouILLÉE: "L'Homme automate", 554.
} 


\section{Automatismo psíquico y movimiento orgánico}

Nietzsche defiende, a diferencia de Pereyra y Descartes, la existencia de un «automatismo animal» que en sus diversas manifestaciones se presenta con un elemento psíquico. El plano más básico, como es el de la acción refleja, parece tener un momento «mental». Donde «mental» no significa racional, ni tampoco «consciente-racional». Nietzsche está hablando de un automatismo inconsciente, donde esta última palabra no significa la ausencia de una actividad inteligente que opera desde un centro. Es más, el cuerpo está plagado de conciencias que, no siendo la «conciencia del yo», permiten desarrollar una actividad marcada por la capacidad de autorregulación. Para Nietzsche, el organismo más ínfimo se desenvuelve desde un grado de «conciencia» ${ }^{17}$.

Insistimos que cuando se usa la palabra «conciencia» en este nivel, no piensa Nietzsche en la «razón» de Pereyra y Descartes, sino en cierto tenerse presente básico. Para decirlo de algún modo, así como desde la «razón lógica-consciente» el hombre «dice yo», el cuerpo y los organismos más básicos «bacen yo». Por ello, la importancia que asigna Nietzsche a esos precursores del pensamiento moderno, consiste en que han dado pie, sin duda sin quererlo, para desarrollar la idea que patentiza que en un gran espectro del mundo orgánico, la vida puede desenvolverse sin el concurso de la «razón»y la «conciencia».

Se advierte, entonces, que la perspectiva de Nietzsche está lejos de dudar del carácter «vital», «sensible» y «animado» del animal. Por ello, lo que podemos encontrar en sus escritos son argumentos que, dejando de lado ese asunto que ocupaba a Pereyra y Descartes como es el de explicar el movimiento animal en términos físicos, se centran en descartar cualquier proceso puramente mecánico en la actividad corporal.

Aquí es donde la honestidad inicial de una explicación mecánica de la actividad animal se vuelve, para Nietzsche, insuficiente. Por lo mismo, en este nivel es donde se hace más evidente el desprecio - al parecer no querido- de la sensibilidad en el que deriva el fisiologismo. En otras palabras, al explicar ciertos fenómenos desde una perspectiva anclada al «automatismo puro» se restringe la comprensión de la vida animal y se revela con mayor claridad su visión limitada respecto al real alcance de la «sensibilidad». En efecto, sucede que parte del mundo moderno al extrapolar las ventajas metodológicas de la perspectiva cartesiana más allá del plano analítico, reduce el alcance de la actividad sensible y desvirtúa la visión de la actividad psíquica y vital. Nietzsche, por su parte,

17 F. NiETzSCHE: Kritische Studienausgabe. Walter de Gruyter, München 1999, XI, 25 [401], 116. (En adelante KSA). 
superando esta limitación, reconoce que estudiar al cuerpo como si fuera una máquina, no es lo mismo que afirmar que este sea, efectivamente, una máquina.

\section{Lo psíquico de la actividad nerviosa}

Nietzsche concuerda con varias tesis de los fisiologistas y no tardaría mucho en defender el principio en que se basa Ribot, según el cual «toda actividad psíquica implica una actividad nerviosa». Sin embargo, consideramos que negaría la recíproca como es la de sostener que «toda actividad nerviosa no implica una actividad psíquica» ${ }^{18}$.

Ahora bien, para hacer evidente que Nietzsche no puede estar de acuerdo con la existencia de una actividad puramente nerviosa sin presencia de un elemento «psíquico», basta con que atendamos a su concepción de la actividad orgánica.

Fijémonos tan sólo en un fenómeno del mundo orgánico, a saber: la memoria ${ }^{19}$. Ella opera en todo el organismo y su actividad se ejerce desde diferentes centros. Por ello, el mismo surgimiento de las respuestas reflejas, no sólo las condicionadas, depende de la potencia retentiva. Sucede que, desde Nietzsche, podríamos afirmar que no sólo el «reflejo condicionado» es algo devenido y adquirido, sino también, los llamados «reflejos innatos» $»^{20}$. Tengamos en cuenta que Nietzsche, patentizando la amplitud de la memoria, sostiene que «todos los nervios, por ejemplo, en las piernas recuerdan experiencias pasadas» ${ }^{21}$. Para Nietzsche, en lo orgánico no hay olvido, pero, esto no quiere decir que todo lo

\footnotetext{
18 Th. Ribot: Las enfermedades de la personalidad. Daniel Jorro, Madrid 1912, 8.

19 Aunque Nietzsche extiende la «memoria» a lo que se conoce como «mundo inorgánico».

20 Como es obvio, Nietzsche no conoció los trabajos de Pávlov respecto a los reflejos condicionados. Sin embargo, debe haberse enterado por diversos medios (Paulhan, Fouillée, Richet, etc.) del trabajo de su maestro Sechenov. No podemos dejar de mencionar que Nietzsche leyó el texto de Alexander Herzen (hijo) Physiologie de la volonté (Germen Baillière, Paris 1874) con Paul Rée (la traducción, del italiano al francés, pertenece a Charles Letourneau que es, también, un autor leído por Nietzsche), escrito que contiene más de un capítulo dedicado a las «acciones reflejas». Ahora bien, solo para ilustrar la densa trama de relaciones intelectuales que Nietzsche componía, recordemos que es el mismísimo Herzen quien le comunica a Nietzsche, no sabemos por qué medio, que Rée le devuelva el libro a su dirección en Florencia, debido a que es el único ejemplar que tiene (Cfr. Carta a Rée, 07 de mayo de 1877). Nietzsche conocía a los hermanos Herzen, debido a que eran hijos adoptivos de su amiga Malwida von Meysenburg.

21 KSA IX, 2 [68], 44. Cfr. P. MARTínez BECERrA: Nietssche y el despliegue de la libertad. Ril, Santiago de Chile 2007, 77.
} 
incorporado sea significativo. El organismo se acondiciona, inteligentemente, para «reflejar» tan solo determinados estímulos.

Siendo coherentes con la doctrina nietzscheana de la voluntad de poder, cabe afirmar que el criterio de esta adecuación al mundo exterior propia del reflejo es el fomento de la propia vida del organismo. En este sentido, sostiene Nietzsche que «el número de estímulos es muy exiguo en comparación con la multiplicidad de efectivos motivos estimuladores —en este hecho tiene su raíz el error más antiguo» ${ }^{22}$. En lo orgánico hay un criterio de selección, igualación e identificación de casos que viene a ser un discernimiento centrado en el crecimiento y en el menor gasto de energía. La posibilidad de reacción ante un estímulo determinado y no a otro, es ya un producto devenido de la fuerza plasmante, interpretante y activa que opera en lo vivo. El mundo de los estímulos es un mundo filtrado (falseado), transpuesto, desde antiguas experiencias que se han incorporado como hábito. En este sentido, afirma Nietzsche que en el hombre, «Toda la 'experiencia interna' se funda sobre una irritación de los centros nerviosos, a la cual se busca y se imagina una causa [...] esta causa no es en absoluto adecuada a la causa real, es una búsqueda que tantea en base a la pasada 'experiencia interna', es decir, en la memoria. Sin embargo, la memoria conserva también el hábito de la vieja interpretación, es decir, de la causalidad errónea...» ${ }^{23}$.

Hay que agregar que, según parece, de un acto reflejo puramente mecánico, no sería posible dar un salto a la actividad psíquica. Esto se encarga de defender Fouillée, a instancias de Spencer. Es decir, si este último quiere hacer proceder toda la vida psíquica del acto reflejo del mismo modo que lo hace Sechenov, ha de atribuirle algo de mental. Por ello, no tarda en hacer ver que Spencer, tal vez contradiciéndose, se aleja de una concepción de la «acción refleja entendida como simple transmisión mecánica», cuando en los Principios de psicología afirma que «la acción refleja es la forma más inferior de la vida mental» ${ }^{24}$. El mismo Fouillée pregunta: «¿cómo una acción refleja entendida como simple transmisión mecánica y con exclusión absoluta de todo elemento de orden mental puede ser la forma más inferior de la vida mental? ${ }^{25}$. Fouillée responde, coincidiendo esta vez con Nietzsche: «es posible concluir que lo mental existe ya en el 'reflejo' pretendidamente automático» $\mathrm{y}$-continúa el filósofo francés en aparente acuerdo con una

22 KSA IX, 11 [270], 545. Cfr. P. MARTíneZ BECERRA: Nietzsche y el despliegue de la libertad, 58.

23 KSA XII, 15 [90], 459.

24 A. FOUILLÉE: “L’Homme automate”, 569.

25 Ibíd. 
de las tesis más atrevidas de Nietzsche- «que antes de la vida ya está en el fondo de los movimientos llamados inorgánicos; que antes que todo lo mental está entre los factores primitivos de la evolución $\rangle^{26}$.

Ciertamente, para Nietzsche, la exigencia de una actividad refleja que presenta un elemento psíquico, no viene dada tanto por la imposibilidad de dar un salto de lo puramente mecánico a la conciencia del yo, sino por su concepción de la vida como voluntad de poder. Recordemos que la voluntad de poder opera desde dentro, por lo que no pueden haber simples reacciones. La vida es creativa desde el interior y no meramente reactiva. La acción refleja no opera del mismo modo que un resorte cuando se le hace saltar, puesto que en ese centro nervioso debe darse un momento «perceptivo», es decir, un estímulo debe ser interpretado ${ }^{27}$. El movimiento reflejo expresa, en no escasa medida, cómo el cuerpo se acondiciona para desenvolverse con seguridad y rapidez en sus procesos de apropiación. En todo lo orgánico hay procesos valorativos, interpretativos y hermenéuticos, que son cruciales en la constitución de la actividad refleja.

Nietzsche destaca que la actividad refleja, la reacción, no se suscita a causa del dolor. Es decir, ese momento psíquico, a su entender, es posterior. Expresa Nietzsche que «en casos imprevistos la reacción viene, si se observa exactamente, manifiestamente primero que la sensación de dolor. Saldría mal parado si, dando un mal paso, yo debiese esperar que suene la campana de la conciencia y me telegrafiase una señal de lo que debo hacer ${ }^{28}$. La reacción, así como el dolor concomitante, viene a ser manifestación de elementos atávicos incorporados en el desenvolvimiento de la vida individual. En la acción refleja «hablan» experiencias pasadas incorporadas y transmitidas por herencia. En este mismo sentido se expresa Nietzsche cuando quiere dar a entender de qué se trata ese fenómeno que llamamos «dolon»: «No es la herida, la que hace mal: es la experiencia de las consecuencias nocivas que una herida puede acarrear para todo el organismo, es aquella experiencia que habla en forma de agitación profunda que se llama dolon» ${ }^{29}$.

\footnotetext{
26 Ibíd.

27 Cfr. L. Bourdeau: El problema de la vida. Fernado Fé-Saenz de Jubera, Madrid 1902, 57.

28 KSA XII, 14 [173], 359.

29 Ibíd.
} 


\section{E1 cuerpo como pluralidad psíquica}

Ya hemos establecido que Nietzsche considera que donde existe un organismo, hay una constitución de «conciencias» donde esto significa que hay elementos individuales y con un buen grado de autonomía. En esto hay coincidencia con Goethe, Haeckel, Virchow, Pflüger, entre otros. Tengamos en cuenta que Pflüger, defendía que la naturaleza del reflejo es la de un «mecanismo inteligente» y considera que la estructura nerviosa que posibilita dicha acción posee «capacidades 'psíquicas'»"

Estas ideas de pluralidad de individuos al interior del cuerpo, sirve de base para dejar de dar a la conciencia un rol centralizador por excelencia. Esta es una gran estocada al «yo pienso» cartesiano. Como ha señalado Barbara Stiegler, una buena parte de la argumentación nietzscheana que permite la «descentralización del sujeto viviente» de la conciencia racional, la encuentra en la teoría celular de Virchow ${ }^{31}$. Este último, en su libro Patología celular de 1858, sostiene: «Vemos, pues, que el organismo elevado, el individuo, resulta siempre de una especie de organización social, de la reunión de muchos elementos puestos en contacto, es una masa de existencias individuales, dependientes unas de otras, pero esta dependencia es de tal naturaleza que cada elemento (célula, o, como dice perfectamente Brücke, organismo elemental) tiene su actividad propia; y aun cuando otras partes impriman a este elemento una impulsión, un excitación cualquiera, la función no deja de emanar del mismo elemento, y de ser, digámoslo así, personal» ${ }^{32}$.

Puede causar extrañeza que Virchow, pese a afirmar lo anterior, confiese que «es casi imposible tener ideas más mecanicistas que las que yo profeso» ${ }^{33}$. El mismo asombro puede suscitar Haeckel, discípulo de Virchow cuando, una vez que asigna, también, esta suerte de yoidad a la célula, pretende seguir siendo materialista. En otras palabras, llama la atención que Virchow atribuyendo una ciudadanía republicana a la célula considere que sólo puede cambiar por medio de un estímulo externo ${ }^{34}$.

\footnotetext{
30 M. JEANNEROD: De la fisiología mental. Historia de la relación entre la biología y la psicología. Dolmen, Santiago de Chile 1999, 120-121.

31 Cfr. B. STIEGLER: Nietzsche et la biologie. PUF, Paris 2001, 22.

32 R. VirCHOw: "Fragmento de Die Cellularpathologie", en Panorama histórico de la Ciencia Moderna, Guadarrama, Madrid 1962, 710. Se pueden encontrar datos complementarios en P. MARTÍNEZ BECERRA: "Nietzsche y la hermenéutica orgánica", Veritas, 19 (2008), 331-342.

33 Ibíd., 702.

34 Cfr. P. J. BOWLER: El eclipse del darwinismo. Teorías evolucionistas antidarwinistas en las décadas en torno a 1900. Labor, Barcelona 1985, 103.
} 
Parece que cierto terror de que sus tesis sean circunscritas a un «misticismo biológico», le lleva a situarse en el extremo opuesto.

Nietzsche parece no tener este miedo de caer en alguna clase de misticismo al describir la actividad orgánica. Esto se debe a que, según nuestra evaluación, cree saber ironizar con los sistemas científicos ya que los entiende como símbolos explicativos y compendios semióticos cómodos.

\section{Subjetividad corporal y subjetividad yoica}

Como hemos dicho, uno de los objetivos de Nietzsche es la descentralización del sujeto viviente. Esta empresa que tiene como punto de partida la concepción del cuerpo como pluralidad de individuos de Goethe, reafirmada por medio de la Historia del materialismo de Lange, adquiere mayor desarrollo a partir de la histología de Virchow. Por ello, dice Nietzsche que «en un individuo es individual todo, hasta la célula más pequeña» ${ }^{35}$.

Ahora bien, si existen distintos focos vitales al interior del cuerpo que se coordinan y autorregulan, difícilmente se le concederá a la conciencia racional un lugar privilegiado en la unificación de la actividad humana. En este sentido, Nietzsche ocupa más de un concepto para distinguir, a veces de modo bastante maniqueo, el rol centralizador del «yo conciente», de aquel proceso sintético que se lleva a cabo en lo más profundo del organismo. Por un lado, está el «individuo imaginario» (eingebildeten Individuen) que se manifiesta en la actividad conciente y, por otro, el «verdadero 'sistema vital' (wahren Lebens-systeme) que cada uno es» ${ }^{36}$. Por una parte, se muestra un espíritu inoperante, por otra, el cuerpo con el cual «obtenemos la representación correcta de la naturaleza de nuestra unidad subjetiva» ${ }^{37}$. A un lado, está la «unidad anímica» (seelische Einheit) que es mera sombra de individualidad, al otro, la «unidad fisiológica» (physiologischen Einheit) ${ }^{38}$, el verdadero sustento de la unidad humana.

Ciertamente, en esta liberación de la centralización hegemónica de la res cogitans, Nietzsche utiliza también las propuestas de Roux en torno a la lucha interna de las partes del organismo. Como establece MüllerLauter «a la 'ilusión de la razón' de ser el centro de los procesos corpóreos, Nietzsche contrapone una fórmula repetida de modo textual

\footnotetext{
35 KSA VII, 19 [187], 477.

36 KSA IX, 11 [7], 433.

$37 \quad$ KSA XI, 40 [21], 638.

38 Cfr. P. MARTÍNEZ BECERRA: Nietzsche y el despliegue de la libertad, 130.
} 
del libro de Roux: 'La centralización no es en absoluto perfecta’»' ${ }^{39}$. Más bien, acontece que los movimientos polémicos de estos pequeños focos vitales, gravitan constantemente en distintas direcciones provocando diversas síntesis en su actividad. De estas alternancias, que son, a su vez, cambios en la soberanía al interior del cuerpo, se desprende que la misma individualidad visible, consciente, sea siempre potencialmente variable. Dicho de otro modo, la inestabilidad del cuerpo es, también, la inestabilidad del yo.

\section{Automatismo instintivo y conciencia}

Hemos de destacar ahora, aun más, la preeminencia que Nietzsche da a los «automatismos» de la actividad corporal. Es decir, queremos mostrar cómo Nietzsche describe la actividad segura, inteligente y sin dilación que muestra el organismo a un nivel «subconsciente»y, en especial, al nivel de los instintos. En muchos pasajes, Nietzsche insiste en que la actividad consciente es una actividad que surge de la enfermedad y de la incapacidad, mientras que la actividad que se expresa básicamente mediante la habitud del reflejo y el instinto es de la más alta precisión y elevación. Por ello, Nietzsche considera que el automatismo propio de la actividad instintiva sana, se convierte en el ideal de centralización del desenvolvimiento del quehacer humano.

\section{Concepción del «instinto»}

Para poder dar cuenta con claridad del gran valor que Nietzsche atribuye a la actividad inmediata y automática del cuerpo, frente a la casi nula importancia que le asigna a la actividad tarda e insegura de la conciencia, partamos precisando su concepción del «instinto».

Desde luego, Nietzsche se instala lejos de Pereyra con su concepción del instinto, pues difícilmente podría considerar su actividad siendo similar a la atracción magnética. Para él, el instinto figura como una manifestación de la memoria que, según dijimos, siendo inherente a lo vivo, muestra su poder de organización. Esta organización se lleva a cabo, según lo entiende Nietzsche, «como una especie de abstracción y simplificación» (als eine Art von Abstraction und Simplification) ${ }^{40}$. Se subraya

39 W. MÜLLER-LaUter: "Der Organismus als innerer Kampf. Der Einfluss von Wilhelm Roux auf Friedrich Nietzsche", Nietzsche-Studien, VII, Berlin-New York 1978, 196.

$40 \quad$ KSA XI, 34 [167], 476. 
de modo «lógico», es decir, se reduce a signo lo relevante de una experiencia, pues, de otra forma la retención se vuelve imposible ${ }^{41}$. El instinto viene a ser un hábito en el modo de juzgar el mundo circundante de modo inconsciente, que contribuye a reforzar las condiciones de existencia. En otras palabras, es una modalidad de juicio que posee el cuerpo que le da una propensión a determinada acción. Dice expresamente Nietzsche: «hablo de instinto, cuando un juicio (el gusto en su grado más bajo) es asimilado, de modo que [un ser] se mueve espontáneamente, y no necesita esperar más el estímulo» ${ }^{42}$.

El instinto aparece como un modo de autodisciplina y ahorro inconsciente que es inherente a lo orgánico. En este sentido, viene a ser un modo de acumular experiencia. El cuerpo no gasta profusamente sus energías, no parte nunca de cero, sino que guarda sintéticamente la experiencia pasada en el instinto. El instinto es un prejuicio útil para la vida que concentra en unidad y proyecta hacia el futuro nuestras antipatías y simpatías primordiales. En este sentido, afirma Nietzsche: «sentimientos de simpatía, antipatía, etc., son síntomas de que ya se han formado unidades; nuestros así llamados 'instintos' son tales formaciones» ${ }^{43}$.

Los instintos son, para Nietzsche, juicios orgánicos que, por un lado, pueden nacer y morir y, por otro, presentan grados de complejidad conforme a sus tareas. Por ello, no hay que pensar que Nietzsche, al hablar de la naturalización del hombre esté pensando en una vuelta a los instintos propios de las bestias.

Según Nietzsche, el instinto se forma no a partir de la experiencia del dolor o el placer, sino en el acrecentamiento o disminución de la fuerza. En este plano, el placer y el dolor es un fenómeno intelectual derivado.

La actividad del instinto descansa en una condición que le es connatural: su constante insatisfacción. Al entender de Nietzsche, esta insatisfacción viene a ser un estimulante de la vida y no, necesariamente, una instancia de frustración.

\section{Instinto y voluntad}

El ideal nietzscheano no es el de hacerse cada vez más consciente, tampoco es el de ejercer actos voluntarios. Más bien, considera que el sentido del actuar humano es el de llevarse a cabo, cada vez con más

\footnotetext{
41 Ibíd.

$42 \quad$ KSA IX, 11 [164], 505

43 KSA XI, 26 [94], 175.
} 
facilidad, a partir de ese hilo conductor corporal que es la actividad inconsciente del instinto.

Apoyado en parte de la filosofía de la fisiología de su época, considera que la transformación adecuada es la de pasar de una actividad sujeta a la conciencia racional, a una que tenga su asiento en el instinto. Es más, le parece correcto, junto a Paulhan, que los actos «voluntarios y conscientes» han de tender al automatismo instintivo ${ }^{44}$. Para muchos, esto puede parecer una inversión brutal y poco adecuada, pero, si, efectivamente, queremos centrar la actividad humana en el símismo, en el cuerpo, hemos de centrarnos en los instintos.

Ahora bien, ¿qué significa «movimiento voluntario» en Nietzsche? Ya sabemos que no puede entenderse como movimiento procedente de una facultad espiritual humana ${ }^{45}$. Cabe sostener que la acción voluntaria la concibe Nietzsche de manera semejante a Paulhan, es decir, como una consecuencia y no como causa. $\mathrm{O}$, al decir de Ribot, la acción voluntaria, en general, es un fin y no un principio. En palabras de Nietzsche: «la vieja palabra 'voluntad' sirve únicamente para designar una resultante, una especie de reacción individual que sigue necesariamente a una muchedumbre de estímulos en parte contradictorios, en parte concordantes: — la voluntad ya no 'actúa', ya no 'mueve'...." .

Se puede añadir que el «poder llegar a queren» tiene que ver con una autorregulación interna del cuerpo que, dilatada por ciertas dificultades, se ha hecho consciente. Es decir, hay cierto aspecto «negativo» en la acción voluntaria, en cuanto se la entiende procediendo de una incapacidad de resolución práctica. Paulhan establece que, justamente, se da el acto voluntario cuando «no puede operarse una síntesis espontánea de los fenómenos psíquicos» ${ }^{47}$. Esta incapacidad de resolución puede deberse, por un lado, a que hay déficit de coordinación al interior del cuerpo porque los instintos se muestran enfermos, por otro, a que la relación con el medio externo se complica. Dice Paulhan que «la voluntad es una crisis para pasar de una forma de automatismo a otra generalmente más complicada, adaptada con más precisión a las

44 Cfr. Fr. Paulhan: La fisiología del espíritu. F. Granada y Cª, Barcelona 1907, 173. Tengamos en cuenta que Nietzsche contaba con un libro de Paulhan en su biblioteca, a saber: Les phénomènes affectifs et les lois de leur apparition. Essai de psychologie générale. F. Alcan, Paris 1887. Cfr. G. CAMPIONI - P. D'IORIO - M. C. ForNARI - F. FrONTEROTTA - A. ORsuCCI: Nietzsches persönliche Bibliothek. Walter de Gruyter, Berlin-New York 2003, 432. (El libro de Paulhan no contiene muchas anotaciones por parte de Nietzsche. Sin embargo, Paulhan fue colaborador de la revista de Ribot que Nietzsche leía con pasión). 45 Cfr. P. MARTÍNEZ BECERRA: Nietzsche y el despliegue de la libertad, pp.130-139.

46 A $\int 14,38$ s.

47 Fr. PAUlhan: La voluntad. Daniel Jorro, Madrid 1910, 99. 
necesidades de la vida» ${ }^{48}$. El acto voluntario no parece ser un acto soberano, sino un remedio para volver a organizar el organismo.

De acuerdo a lo anterior, no es de extrañar que, para Nietzsche, el carácter del hombre al cual le atribuiríamos una gran voluntad, se sostenga, a su juicio, en el instinto.

\section{Automatismo corporal y conciencia racional}

La conciencia, al igual que el llamado «deseo razonado», está lejos de operar como facultad. Es más, la conciencia, al igual que la voluntad, manifiesta una cierta incapacidad del organismo a la hora de hacerse cargo de su entorno. Nietzsche sostiene: «El cobrar-consciencia, 'el espíritu', es para nosotros cabalmente síntoma de relativa imperfección del organismo, un ensayar, tantear, cometer errores, un penoso trabajo en el que innecesariamente se gasta mucha energía nerviosa, - nosotros negamos que se pueda hacer algo de modo perfecto mientras se lo continúe haciendo de modo consciente» ${ }^{49}$.

La concepción de Nietzsche es palmaria: la conciencia racional surge a partir de una deficiencia interna o, dicho de otro modo, «en todo volverse consciente se expresa un malestar del organismo» ${ }^{50}$. Por todos lados es posible encontrar en los textos de Nietzsche la idea de una conciencia que no es otra cosa que un síntoma de la cojera del organismo.

Ahora bien, para explicar la genealogía de la conciencia, Nietzsche también destaca su carácter subsidiario y accidental. Al explicar su génesis, propone un origen hipotético, muy al modo de un Rousseau amalgamado al transformismo, que propone que hubo un tiempo en el cual el hombre y las formas orgánicas que le precedieron, poseían instintos tan fuertes que se hacía innecesaria la conciencia. Sin embargo, en algún momento los hombres, debido a ciertas condiciones, no sólo internas sino esta vez también exteriores, «se sentían ineptos para las funciones más simples, no tenían ya, para este nuevo mundo desconocido, sus viejos guías, los instintos reguladores e inconscientemente infalibles, - jestaban reducidos, estos infelices, a pensar, a razonar, a calcular, a combinar causas y efectos, a su 'consciencia', a su órgano más miserable y más expuesto a equivocarse! $\rangle^{51}$.

48 Ibíd., 31.

49 A $\int 14,39$.

$50 \quad$ KSA XIII, 15 [25], 421.

51 F. NIETZSCHE: La genealogía de la moral. Alianza, Madrid 1994, II, \16, 96. 
En esta regresión hipotética, Nietzsche muestra en el origen a un hombre que, siendo una verdadera ave de rapiña, le es indiferente la comunicación y, por ello, vive libre de esa conciencia del yo que, a la postre, se vuelve conciencia moral y «mala conciencia».

\section{La conciencia «casi es algo superfluo»}

De existir un hombre de instintos sanos y eficientes, no estaría necesitado de ayuda, le bastaría para vivir la sabiduría de los mismos y se movería con prescindencia de la comunicación. Sin embargo, cuando en el filosofar nietzscheano ya todo parece ir en la línea de proscribir el rol del acto consciente en todo individuo que se precie de sano, nos encontramos que en el fragmento 11, [316] de 1881, expresa: «cuando un organismo funciona acabado, [la conciencia] casi es algo superfluo ${ }^{52}$. Se advierte allí un subrayado que destaca un «casi» (fast) que, a la vez que manifiesta cautela, da un matiz a su opinión.

La frase está revelando que debe haber consciencia, ya no sólo en los casos en que hay incapacidad orgánica, sino que ella no deja de concurrir, aunque sea mínimamente, en la actividad humana. Sin embargo, Nietzsche, más que considerar con esto que en todo acto está supuesta la conciencia, opina que en la vida humana, aunque sea ésta la más lograda de todas, tarde o temprano se necesita del auxilio de la conciencia. Y hablamos de «auxilio» por ser considerada, aunque a veces Nietzsche lo oculte, como el único remedio que puede hacer que el hombre no sucumba.

Hay que tener presente que la conciencia no puede surgir desde sí, sino del cuerpo. Es el mismo cuerpo el que sublima su actividad a un nivel que va más allá de esa autoposesión práctica, propia de aquel que sabe siempre qué hacer, hacia una mirada «reflexivo-espiritual», hacia la contemplación de sí mismo.

La conciencia es el «instrumento» propio de un ser en que la enfermedad se transforma en condición de su modo de vida ${ }^{53}$. Nietzsche parece creer que el hombre habría perecido sin la conciencia y, aun más, que difícilmente sería sin ella propiamente hombre.

En las condiciones de la vida moderna con sus diversas complejidades, sería inútil vivir desde el puro automatismo. Paulhan establece que «las condiciones de la vida humana [...] son tan complicadas, que el hombre no ha podido llegar al automatismo». Sin duda, Nietzsche no podría menos que asentir este juicio y tampoco podría negar lo que a

\footnotetext{
52 KSA IX, 11, [316], 563.

53 KSA XI, 37 [4], 557.
} 
continuación sostiene Paulhan: «La oposición de las tendencias o la insuficiencia del instinto, son provocadas o descubiertas a cada momento por las contradicciones de la vida social $[\ldots]\rangle^{54}$.

Con lo dicho, ¿acaso no parecería más coherente culpar al cuerpo y a sus instintos de la enfermedad de la conciencia? Tal vez, pero lo que esta claro es que, para Nietzsche, se han de formar nuevos instintos para poder enfrentar las nuevas complejidades. Es ahí donde se sitúa el verdadero progreso y la verdadera libertad humana. Por ello, la conciencia debe entenderse como un instrumento subsidiario que ha de permitir el paso hacia un automatismo instintivo más complejo y elevado. Sin duda, Paulhan no está diciendo algo muy distinto a Nietzsche, sin embargo, es más claro a la hora de reconocer que la vida humana siempre está transitando del automatismo a la conciencia y viceversa. Es evidente que Nietzsche es reactivo frente a los que entienden la actividad consciente como la máxima expresión del hombre y que defienden el primado de una conciencia que se entiende a sí misma desligada del cuerpo y sus funciones.

En coherencia con esta doctrina, Nietzsche plantea reemplazar la educación moral, totalmente ineficiente en tanto sujeta a la ficción del libre arbitrio, por una cría del hombre. Se ha de buscar acondicionar el cuerpo en vez de «moralizar». Sostiene Nietzsche: «consecuencia práctica: modificación de los caracteres; cría en lugar de moralización. Trabajar con la acción directa sobre el organismo, en lugar de la acción indirecta a través de la disciplina ética» ${ }^{55}$.

Sin duda, esto último planteado por Nietzsche es doctrina peligrosa. Sin embargo, el mismo replicaría que el carácter peligroso de una idea no tiene por qué ir de la mano de la falsedad.

\section{Conclusión}

Hemos partido nuestra reflexión fijándonos en el automatismo de los brutos defendido por Pereyra y Descartes. Detrás de esta concepción comparece, en el caso de Descartes, la distinción entre la res cogitans y la res extensa. El primer mundo es el mundo de la razón y, el segundo, el mundo mecánico de la causalidad natural. La actividad cuerpo, perteneciendo al mundo de la necesidad, se subordina a las leyes físicas. Por tanto, en esta concepción, el cuerpo se analiza desde un prisma puramente mecánico.

\footnotetext{
54 Fr. PAULHAN: La voluntad, 22.

$55 \quad$ KSA X, 7 [97], 275.
} 
Nietzsche piensa que empezar a estudiar el movimiento del cuerpo, tratando de explicarlo prescindiendo de las causas espirituales, constituye el gran mérito de Descartes. Sin embargo, situándose en una perspectiva antidualista, Nietzsche va a considerar la propuesta de Descartes como el paroxismo del centralismo de la razón.

Justamente, intentado superar el raciocentrismo dualista de Descartes, Nietzsche se queda sólo con su res extensa, pero la transforma completamente y la libera de la interpretación materialista y mecanicista. Para ello, ciertamente, debe dar otra imagen física del mundo más cercana al dinamismo de Leibniz. El mundo le parece activo desde dentro y, una buena parte de él, se muestra en su desarrollo como pluriperspectivo. Este último ámbito de la realidad es el que se ha venido a llamar «mundo orgánico».

El animal pertenece a este último grupo de seres y si bien no posee, para él, ni conciencia, ni razón, ni voluntad, puede desarrollar una notable actividad automática. A juicio de Nietzsche, esto se debe no a que el bruto responde mecánicamente a las leyes físicas, como pensaba Pereyra y Descartes, sino a la inteligencia de su cuerpo que ha devenido en instintos. Lo mismo ocurre en el hombre: en su interior se da una lucha de instintos que se sintetizan, cuando éste está sano, en una actividad ágil y automática.

Nietzsche piensa que la sabiduría del cuerpo no se ha valorizado lo suficiente. Un síntoma de ese desprecio es creer que el centro de la actividad es la conciencia. Nietzsche, proponiendo una más de sus inversiones, muy a tono eso sí con muchos fisiólogos de la época, estima que en el despliegue humano, el automatismo instintivo ha de ser la regla y la actividad consciente la excepción.

El verdadero hombre sintético, acabado, es aquel que ha cultivado sus instintos hasta configurar su «carácter». «El genio se asienta en el instinto», nos dice Nietzsche refrendando lo anterior. El automatismo instintivo es, para él, el fundamento de todo gran hombre. Por ello, las figuras admiradas y denostadas por Nietzsche, siempre se enfrentan a un tribunal que tiene como medida para asignarles valor, el mayor o menor predominio de la actividad instintiva. Tengamos presente la imagen que Nietzsche se hace de Goethe. Tenemos en ella, al ideal del homo natura adscrito no a esa conciencia del yo que tempranamente se hace moral, sino al despliegue de la naturaleza. Este despliegue del ser de Goethe, como sostenía agudamente Amiel, no es moral, es estético, porque el mismo es manifestación de la naturaleza. Por ello, nos dice el sufrido Amiel, que Goethe es sordo al dolor del mundo y a la voz de la conciencia y, a causa de ello, incapaz de remordimiento. 
A nuestro entender, la misma metáfora nietzscheana del superhombre, del sentido buscado pero nunca alcanzado, es equivalente al «llegar a ser lo que se es» a partir del automatismo de nuestros instintos. La conciencia, al entender de Nietzsche, desgarra al hombre de su centro y, en esa misma medida, le hace dudar, titubear y le resta libertad.

Sumario: I. Automatismo mecánico y movimiento animal; 1. Automatismo y sensibilidad; 2. Automatismo y conciencia; II. Automatismo psíquico y movimiento orgánico; 1. Lo psíquico de la actividad nerviosa; 2. El cuerpo como pluralidad psíquica; 3. Subjetividad corporal y subjetividad yoica; III. Automatismo instintivo y conciencia; 1. Concepción del «instinto»; 2. Instinto y voluntad; 3. Automatismo corporal y conciencia racional; 4. La conciencia «casi es algo superfluo»; Conclusión. 